\title{
An Exploration of The Perceptions Regarding Parental Involvement in The Academic Activities of Secondary School Students at City Kotli AJK
}

\author{
Saira Farooq Shah ${ }^{1 *}$, Razia Rizve ${ }^{1}$, Kiran sarfaraz $^{2}$, and Maryam Iqbal ${ }^{2}$ \\ ${ }^{1}$ Assistant Professor, Mirpur University of Science and Technology, MUST 10250 Mirpur \\ $\mathrm{AJ} \& \mathrm{~K}$
}

${ }^{2}$ M. Phil Scholar, Mirpur University of Science and Technology, MUST 10250 Mirpur $\mathrm{AJ} \& \mathrm{~K}$

\section{ARTICLE INFO}

\begin{tabular}{l}
\hline Keywords: \\
Parental Involvement \\
Academic Activities \\
Students Performance
\end{tabular}

\begin{abstract}
The world is becoming more and more competitive and the quality performance is the key for personal progress. Excellence particularly in academic and generally in all other areas has been seen as an important aspect. The good academic performance of the children is the strongest pillar in the building of a healthier community. The purpose of conducting this research study was to check and explore the involvement of parents in the academic activities of the students. A quantitative research approach was used for this study with class $10^{\text {th }}$ present students of 15 government and private schools of Kotli City through random selection. Survey design was used for data collection by distributing two set of questionnaires to both parents and their children's. After analysis of the data the researcher found that the involvement of parents in children's education not only facilitates their children's but also it significantly influenced nation as a whole. Thus, the research study recommends the parents to facilitate and provide the good learning environment to their children's by showing involvement in children's activities at home to educate the bright stars of the future more accurately towards the path of prosperity. This will help to increase the level of academic achievement of students.
\end{abstract}

\section{Introduction}

The academic achievement of students has been affected by the involvement of parents in children educational activities (Wilder 2014). The involvement of parents in student's activities throughout primary, secondary, and higher secondary level creates positive influence on the educational outcomes of their children (Loomans, 2014). The educators and policy makers appreciate the involvement of parents in their children's education and also their participation in school. The connection among parents and school administration is a useful method for increasing the educational strength of their children. Many research studies found that some students show higher educational performance while other shows moderate or weak performance in the school because of the level of their parents' interest and involvement in their educational activities. Alba, Sloan, Sperling (2011) stated that the parents who show more involvement in their children's activities have higher educational wishes from them. Graves and Wright (2011) clearly stated the role of parents and their

* Corresponding Author E-Mail Address: saira.edu@must.edu.pk 
involvement creates positive influence and has been recognized by the administration of the school and also by the policy makers. The educational success of students is directly connected with involvement of parents; it enables them to perform well in school Miller (2000). The involvement of parents in educational activities is necessary for all the children but the level of parental involvement varies due to their qualification and socio-economic status (Schneider and Lee 1990). It has been found that the involvement of parents in their children's academic activities increase the attendance rate of their children in the school, help them in completing their home assignments very well and also modify their behavior towards education (Trouman, Bickley 1993). The involvement of parents in the educational activities of their children significantly influence the success rate of their children despite of parental level of qualification, their income and family support (Shaver and Walls 1998). Epstein (1992) has elaborated the six dimension of parental involvement that improves the educational career of their children: supporting the parents to help their children in the acquisition of language skills, communication between parents and schools, enable the parents to get involved in the school volunteer programs, involvement of parents in home based learning activities, participation of parents in the decision making procedure of the school, cooperation between the community and school administration. In school settings the involvement of parents in the educational activities is necessary for good academic achievement of students and here the parents play a positive and energetic role which guide the children towards success and prosperity because parents are the first teachers of their children and no one can deny the importance of parents role (Department for children, schools and families 2008, p.17). Without proper help from parents the school staff may not be capable of implementing many learning procedure (Mji and Makgato, 2006).

\subsection{Research Objective}

The objective of this research paper was to explore the extent of parent's involvement in the academic activities of their children.

\subsection{Significance of the Study}

Parental involvement in student's educational activities creates significant impact on their educational outcomes. Now a day's parent's involvement can play major role in the educational success of children. Therefore, observing the importance of parental involvement the researcher has explored the extent of parental involvement of secondary school students in city Kotli AJK.

\subsection{Statement of the Problem}

The involvement of parents in student's affairs creates positive impact on student's performance in the school. The researchers have explored the parental participation in the educational success of secondary school students at city Kotli AJK.

\section{Literature Review}

Parental involvement in students' activities plays a crucial role in shaping the personality and future of their children. The participation of parents and families in children's affairs at early stages leads them towards a bright future (Barbarin and Aikens, 2008). Parents are first teachers of their children, from the initial stages of their lives they learn from their parents, very keenly observe them and further utilize the parental observations in their practical lives. The difference which exists between student's scores and performance is due to parental involvement in their children activities, parental values and home experience of child which their parents provide them at home. Woods, \& Schweingruber (2009) stated that the behavior of parents provides guide line to their children, therefore it is necessary for parents to be 
aware of the impact of their involvement in students activities at home. The involvement of parents in children affairs in different ways is the central parameter for child's better educational achievement (Turner and Midgley 2010). In this research paper the researcher has highlighted some important factors which plays significant role in the level of student's academic achievement: the aspirations of parents, connection between parents and children, the arrangements of home, and most important the involvement of parents in school-based activities (Wang, 2004). Moreover, few other factors also contributing in student's academic achievement are the economic status and educational expectations of parents from children (Capraro, and Cetin 2012). The parents of children perform much better in school activities as compare to their peers whose parents show less involvement and concern towards their child's learning (Demir and Unal 2010). The motive of this association is that the parents who show more involvement in student's activities better understand their educational needs and provide all those opportunities which support their children's learning according to their resources (Alomar, 2006). The involvement of parents can enhance the positive progress of children by setting hopes and by providing motivating setup (Cress et al., 2009). Farooq and Berhanu (2011) in their research concluded that educated parents concentrate more on their children learning and their children score are high in the exams as compare to uneducated parents' children. The educational background of parents helps them to better assist their children in their home assignments well and participate in all the programs held in school (Fantuzzo \& Tighe, 2000). The educational outcomes of students are heavily affected by the involvement of parents in the educational affairs to get the top excellence in educational achievement (Barnard, 2004). Less parental involvement and clashes between parents and children cause negative influence on children performance level. Smith and May (2006) stated that the positive interaction of parents and children have a positive function in making children more responsible in the context of education and learning which permit children to step by step take more involvement and interest in their own learning, cooperatively shared the ideas and everyday assignments with others, and give quick response. The researcher used framework of Epstein (1995) as the base of this study as the factors regarding to the involvement of parents. These are parenting, communicating, volunteering, learning at home, decision-making and collaborating with the community. Parenting enables the families to deeply identify the developmental and educational needs of children and also motivate and prepare them for schooling. It also provides guideline to the children at every stage of their schooling and creates a significant home environment that support learning activities at all the stages of learning. Communication involves two-way connection among teachers and parents of the students for the effective progress of students. Learning at home help the parents to utilize the idea how they can best support in homework and in other home-based assignments. The involvement of parents in home-based activities provides a chance to monitor the learning of their children and also assist the teachers to revise the learning of classroom at home. The Epstein framework helps to create a positive correlation between parent's teachers and the students and this will result as the positive achievement of students at all stages of learning.

\section{Methodology}

The purpose of this research study was to explore the extent of parental involvement in the academic activities of secondary school students at city Kotli AJK. The aim of present study was fulfilled by finding the mean values of both students and parents' responses. In this research study the researchers used quantitative method to gather information about the present research problem. In this research study the researchers used cross sectional survey research design for collecting the data. Groves (1996) declared that survey generates data in the numerical shape. Questionnaire is used as an authentic and useful tool for gathering the 
opinions of respondents, and prepared by the researcher with the guidance of research supervisor, it consists of twenty close ended items. One research questionnaire was prepared for the students of current $10^{\text {th }}$ class and second one that was translated in Urdu for better understanding of their parents for checking the scale of parental involvement in the academic success of secondary school students. The researchers utilized five-point rating Likert scale ranging from: Strongly Disagree, 2-Disagree, 3-Undecided 4-Agree and 5-Strongly Agree. The total population was 1423 students in 36 school of Kotli city the researcher took the sample of 381 students from 15 schools.

In this study the researchers used descriptive statistics to find out the mean values of both parents and students' responses. Then the data was represented through graphs and represent the mean values of parental and students' responses on each item. The graphical representation of data indicates how much parents and students agreed or disagreed with the research items.

\section{Data Analysis}

4.1 Analysis of Questionnaire of Students and Parents Data

Parental involvement in student's academics:

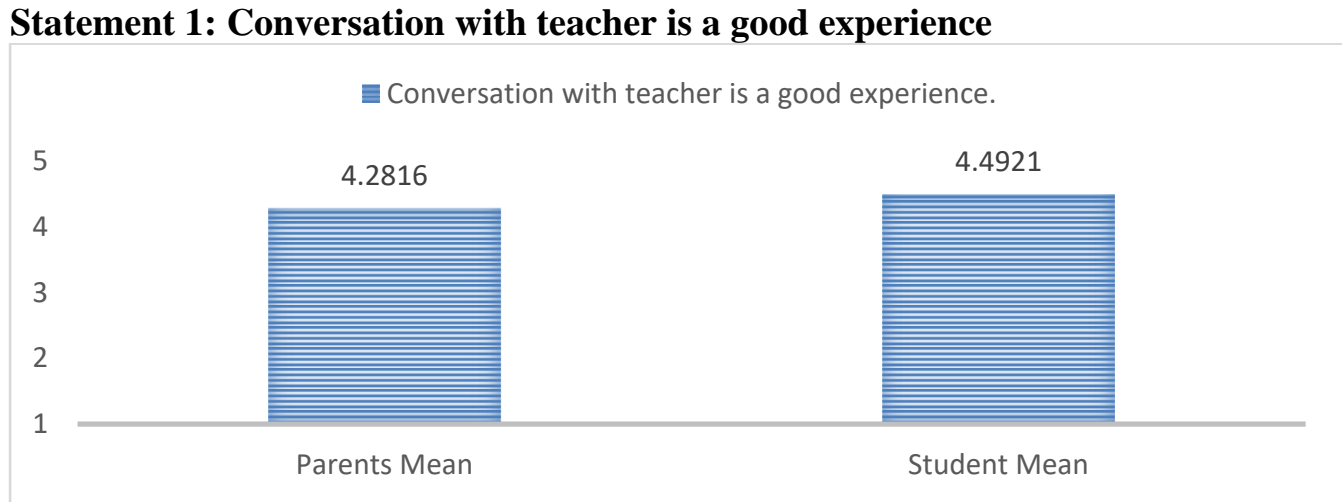

Figure 1. Conversation with teacher is a good experience

The above statement was about the interaction between the parents of students and their school teachers. The mean values of parents and students mean is indicated through the bar chart. Parents mean is 4.2816 and student's mean is 4.4921 . From these values it can be concluded that conversation of parents with the teachers of their children is quite pleasant experience for them. Both respondents strongly agree with the statement.

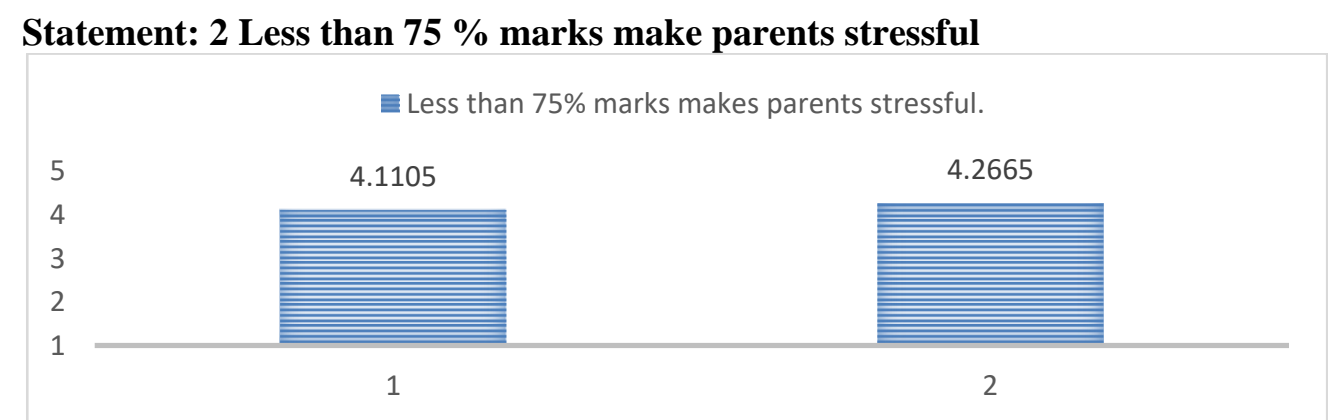

Figure 2. Less than $75 \%$ marks make parents stressful

The above statement was about parent's reaction on bad performance of students. Through the figure mean values are indicated the mean of parents' response is 4.1105 and students mean value is 4.2665 . From the analysis of these values it is concluded that parents and 
students strongly agreed that parents feel stress on less than $70 \%$ marks of their children with a small difference in their responses.

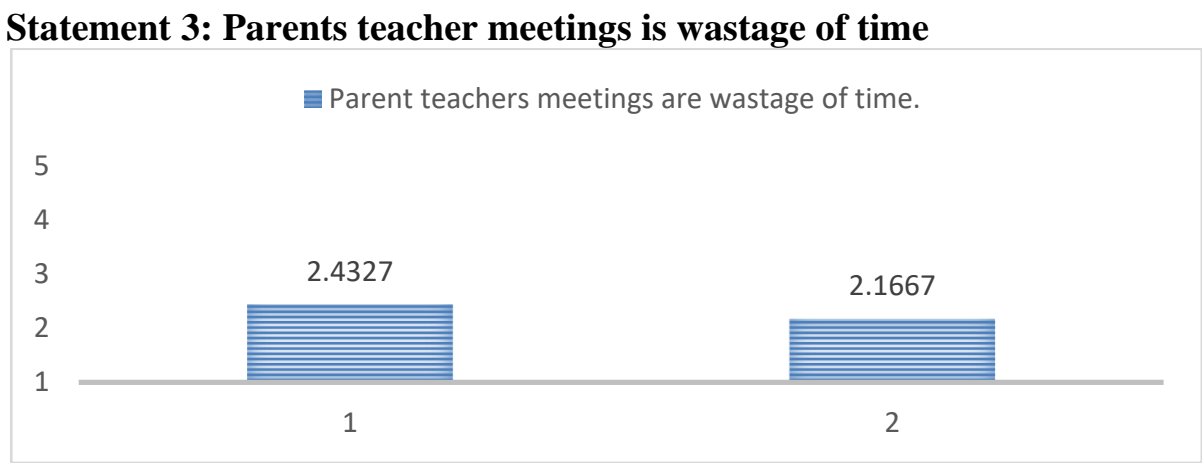

Figure 3. Parents teacher meetings is wastage of time

The above statement indicated that parent's teacher meeting is wastage of time. The above figure shows parents mean as 2.4327 and the mean value of student's response as 2.1667. From these values it can be concluded that no one agree with the statement both parents and students disagree with it with minor difference in their responses.

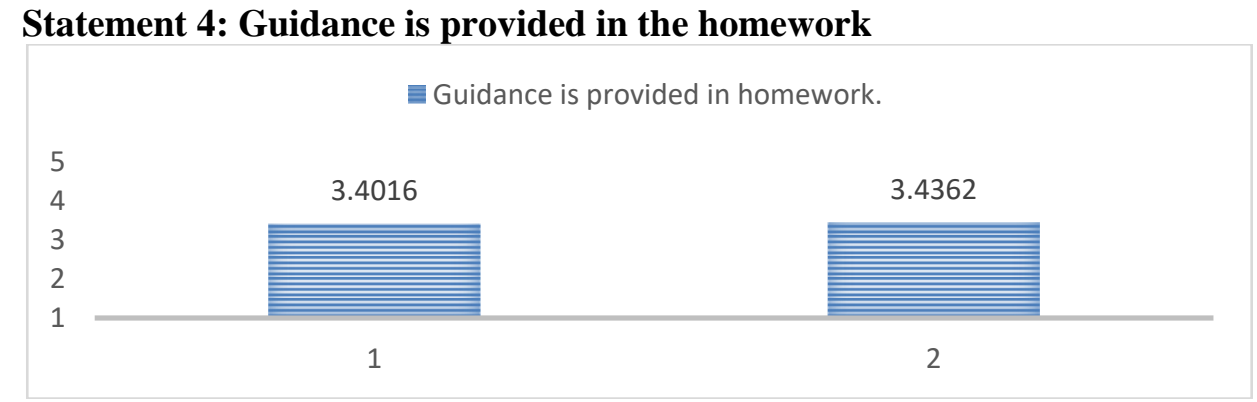

Figure 4. Guidance is provided in the homework

This statement shows that parents provide guidance to their children in their homework. The above figure indicates parents mean as 3.4016 and the value of students mean as 3.4362. From the analysis of these values it can be concluded that parents and students both agree with this statement with a little difference in their response rates.

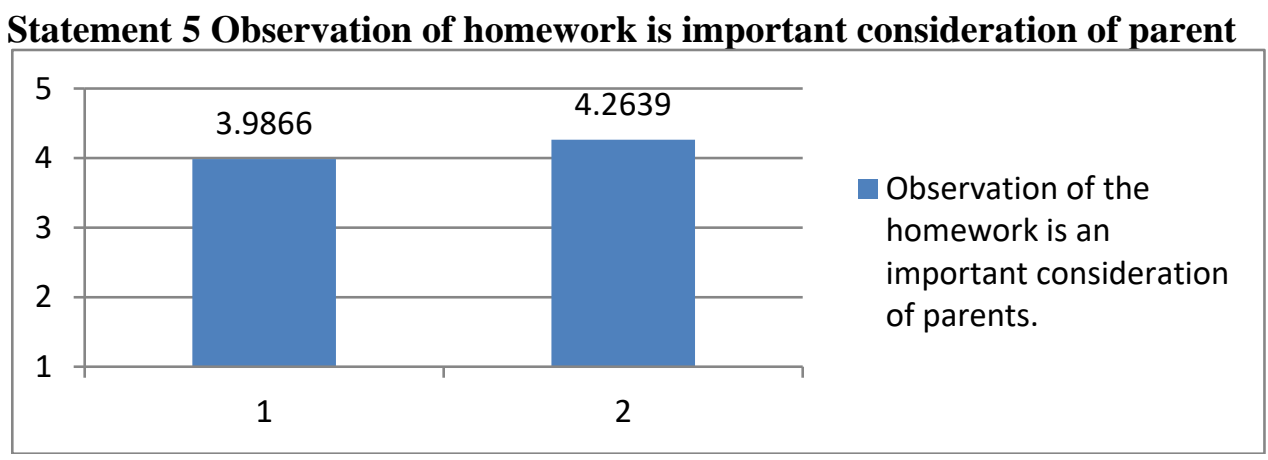

Figure 5. Observation of homework is important consideration of parent

This statement was about homework. The figure indicates values of parents mean as 3.9866 and the value of students mean as 4.2639. From these values it can be concluded that parents and students agree with the statement that checking the homework of children is the top priority of parents with a minor difference in their responses. 


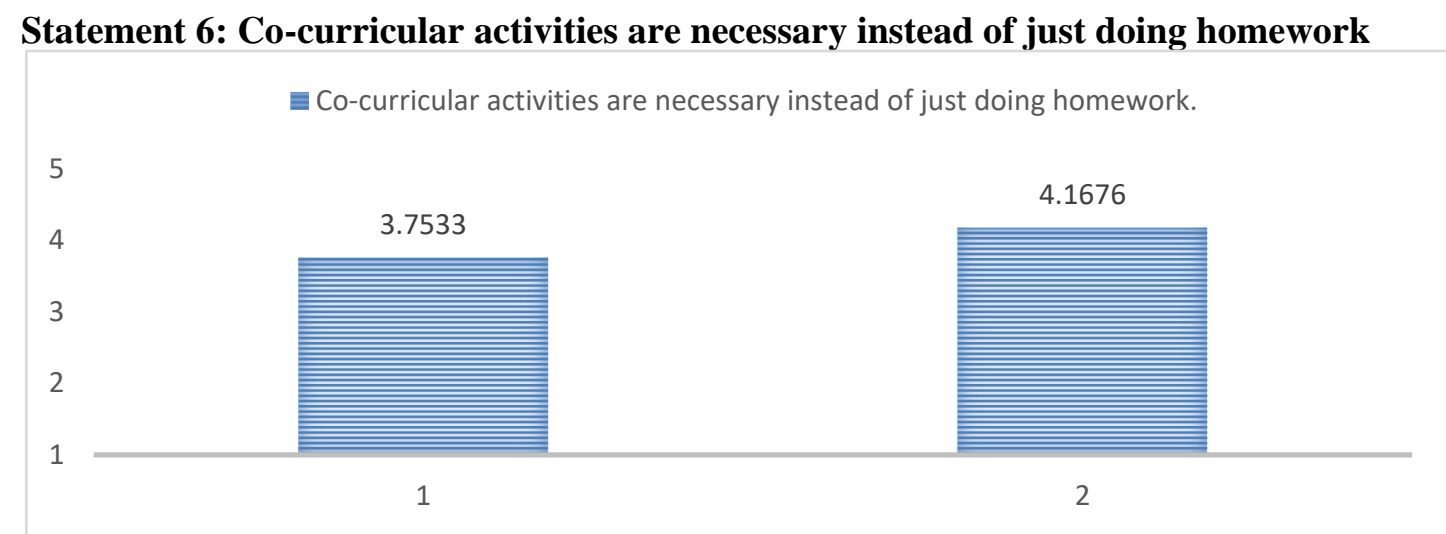

Figure 6. Co-curricular activities are necessary instead of just doing homework

The above statement has elaborated that the co-curricular activities are essential for students. The above figure indicates the parents mean is 3.7533 and students mean is 4.1676. From these values it can be concluded that students and parents agreed that instead of just doing class work students have to participate in all other activities of school with just a minor difference in responses of parents and children.

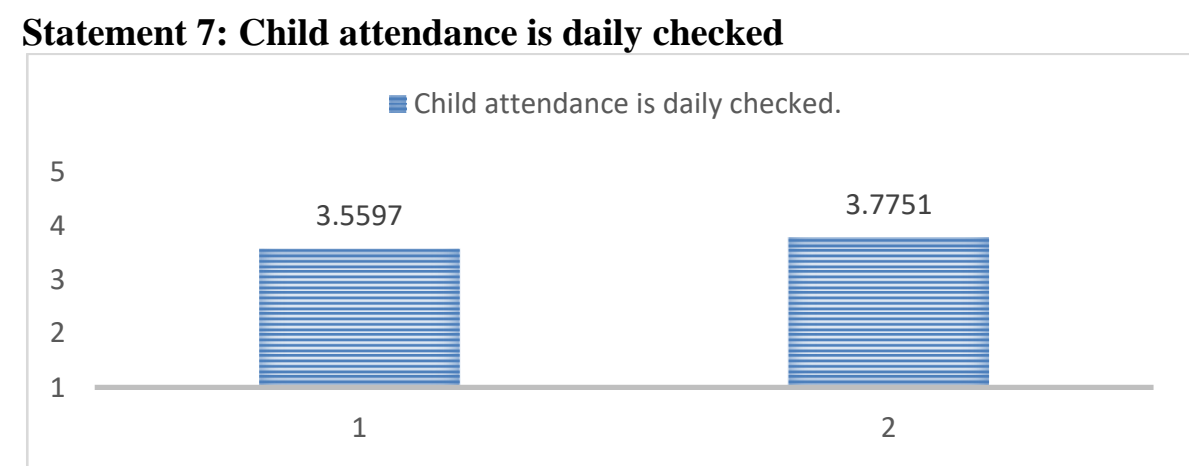

Figure 7. Child attendance is daily checked

The above statement has explained that parents checked the attendance of children on daily basis. The mean of parents is 3.5597 and the mean of student's response is 3.7751. From these values it can be concluded that parents and students agreed with this statement but with a minor difference in their responses.

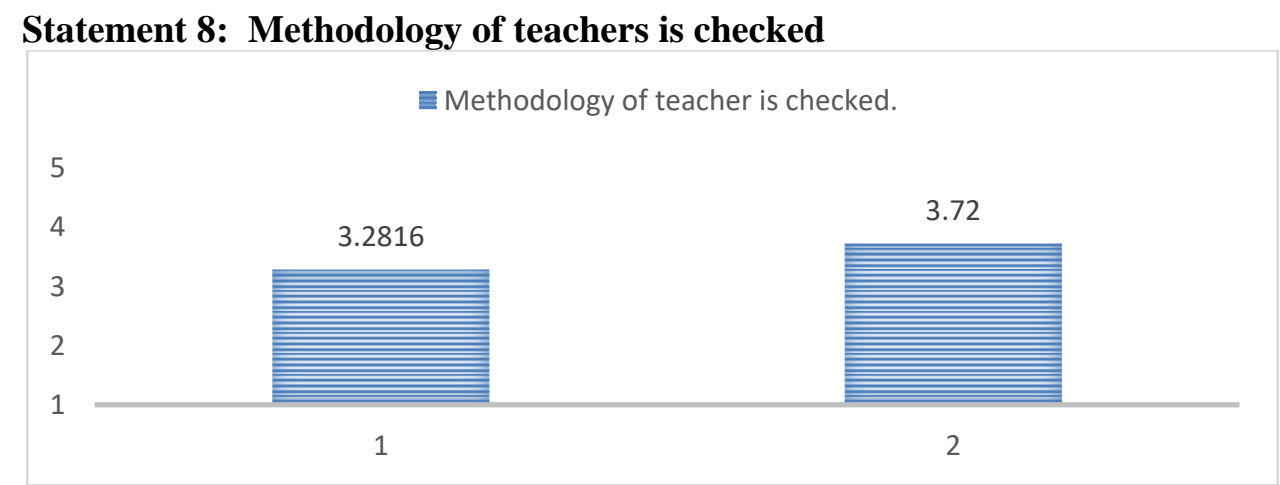

Figure 8. Methodology of teachers is checked

The above statement has explained that parents investigate the method of teachers through which their teachers teach them. The above figure shows the mean of students' response is 3.72 and the value of parents mean is 3.2816 . Through the analysis it can be concluded that 
parents and students agreed that parents check the teaching methodology of teachers but a minor difference present among their responses.

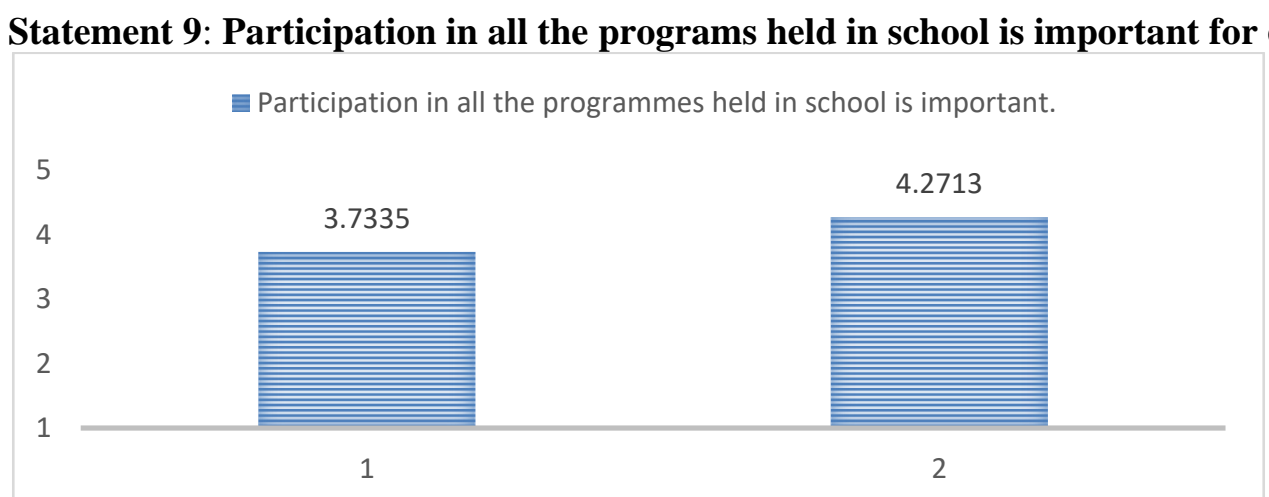

Figure 9. Participation in all the programs held in school is important for children

The statement has explained that the involvement in all the educational activities held in school is essential for all children. The figure shows the value of students mean as 4.2713 and parents mean as 3.7335. From these values it can be concluded that contribution of students in school programs is necessary, parents and students agree with a minor difference in their response rates.

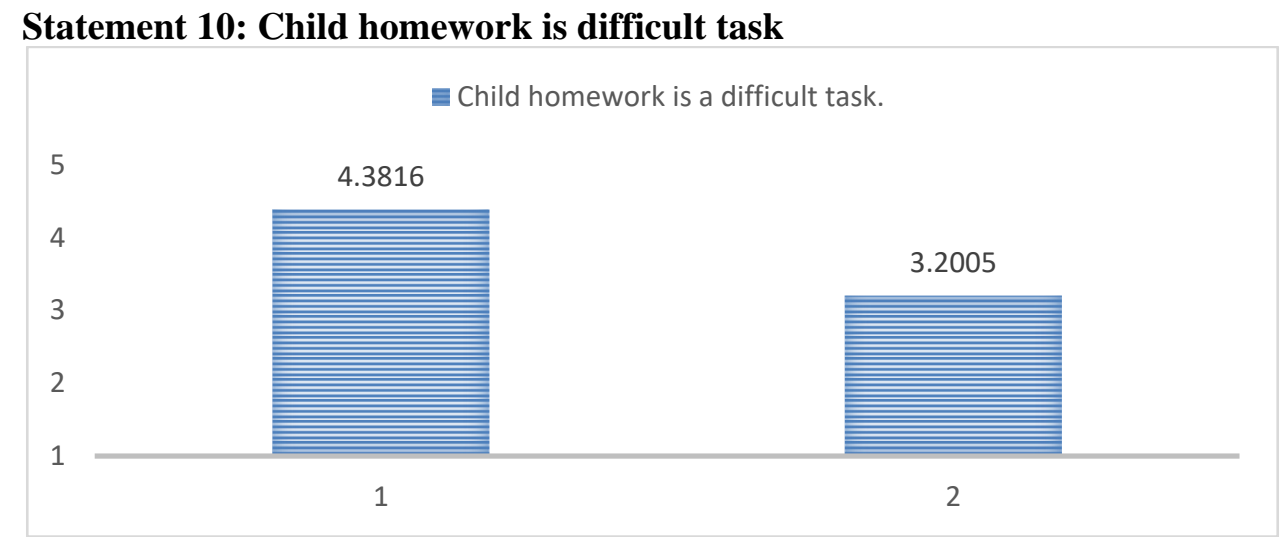

Figure 10. Child homework is difficult task

This statement has explained that parents feel difficulty in the home work of their children because it's tough for them. The figure shows the parents mean value as 4.3816 and students mean as 3.2005. Through analysis it can be concluded that both respondents agreed with this statement but with a minor difference in their responses.

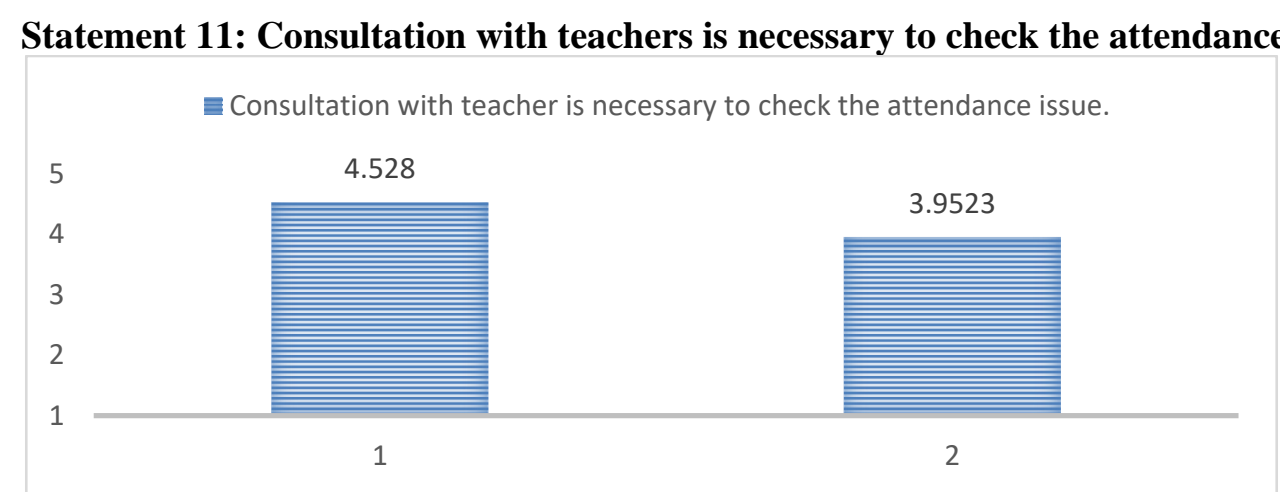

Figure 11. Consultation with teachers is necessary to check the attendance issues 
The statement has explained that it's necessary for parents to monitor the attendance of their children so consultation of parents with school teacher is necessary for checking attendance issues. The figure indicates the value of parents mean as 4.528 and students mean as 4.528 . From the analysis it can be concluded both respondents agreed with the statement but with a minor difference in their responses.

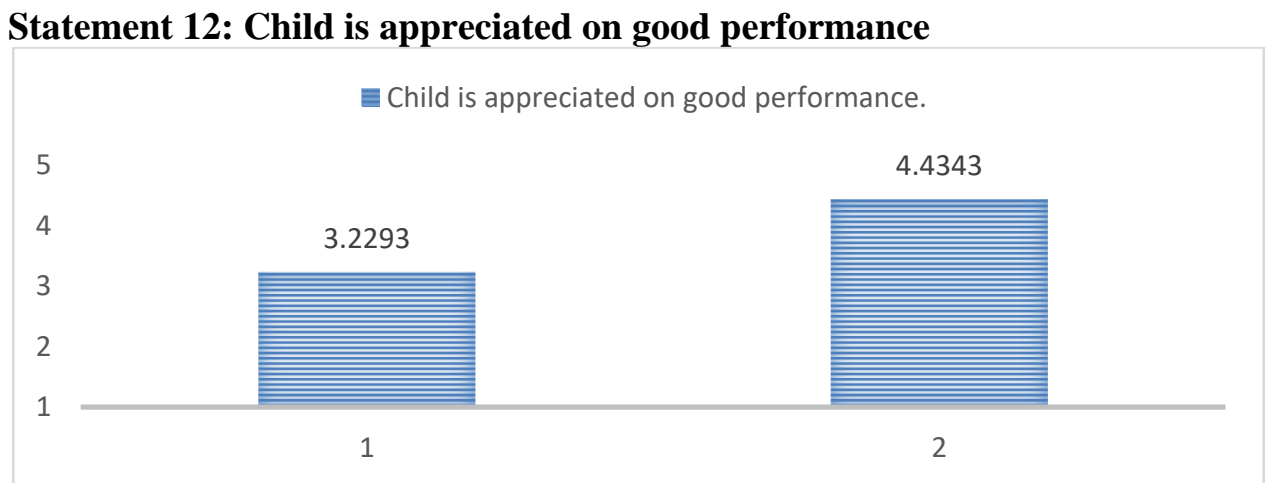

Figure 12. Child is appreciated on good performance

The above statement has explained that parents value the good educational performance of their children. The above figure shows value of parents mean as 3.2293 and means of students as 4.4343. From the analysis of these values it can be concluded that both respondents agreed with the above statement but with a little difference in their responses.

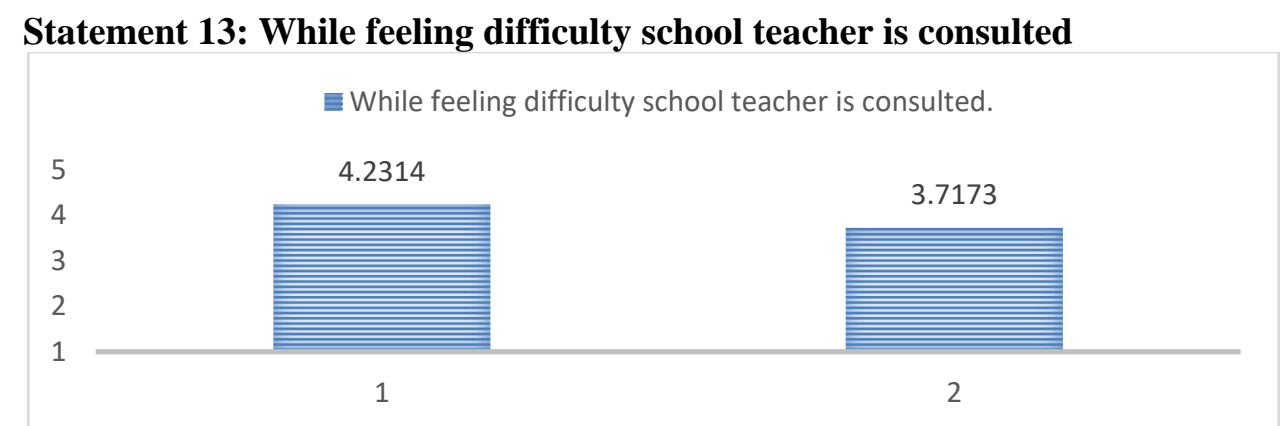

Figure 13. While feeling difficulty school teacher is consulted

This statement has explained that parents consult with the teachers when they feel any difficulty in the homework of their children. The figure shows the values of parents mean as 4.2314 and the value of students mean as 3.7173. From the analysis of these values it can be concluded that both respondents agreed with the above statement but with a minor difference in their responses.

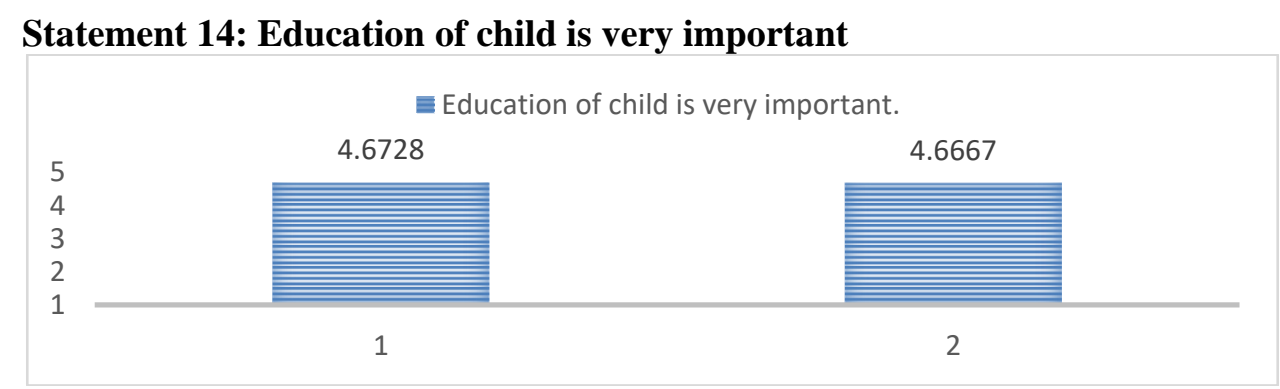

Figure 14. Education of child is very important 
This statement has explained that parents consider that education is very much important for their children. The figure shows the value of parents mean as 4.6728 and students mean as 4.6667. From the analysis of these values it can be concluded that both parents and students agreed with statement with almost same response level.

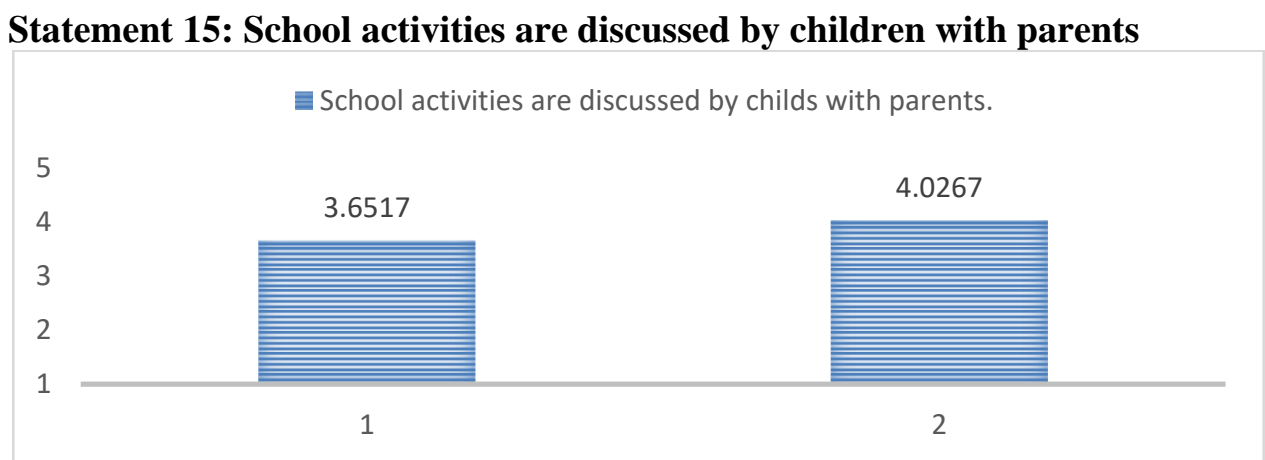

Figure 15. School activities are discussed by children with parents

This statement has explained that the students discuss school activities with their parents daily. The figure indicates the mean of parent's responses as 3.6517 and means students responses as 4.0267. From the analysis of these values it can be concluded that both respondents agreed with the statement just with a minor difference in their responses.

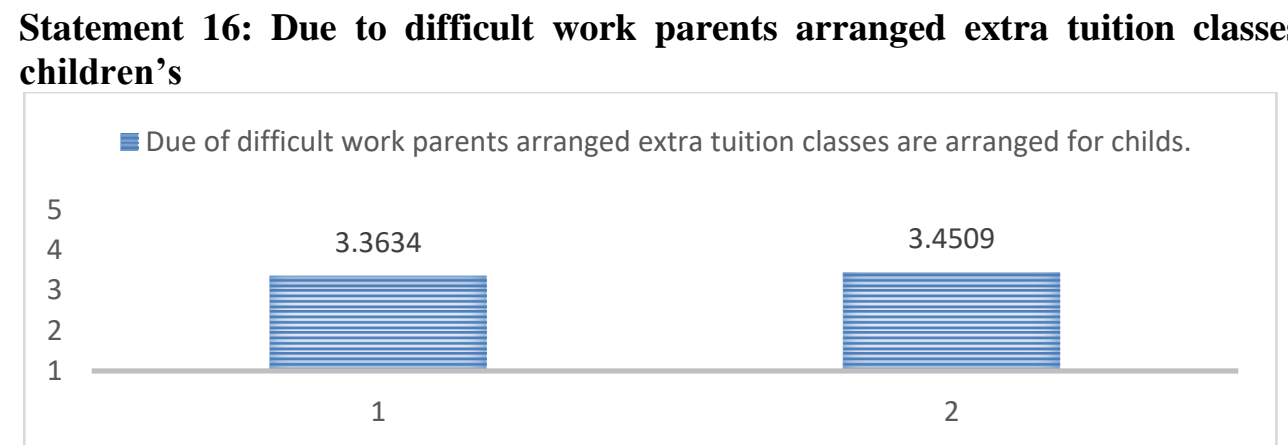

Figure 16. Due to difficult work parents arranged extra tuition classes are arrange for children's

The above statement has explained that parents find the homework of their children very difficult so they arranged extra tuition classes for their children's. The figure indicates the students mean as 3.4509 and parents mean as 3.3634. From the analysis of these values it can be concluded that both respondents agreed with the above statement.

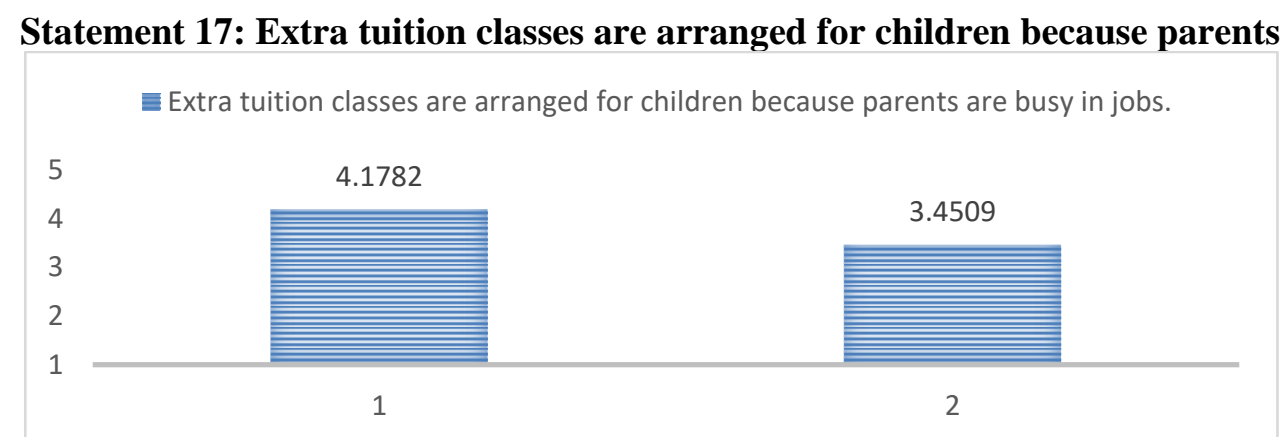

Figure 4.17. Extra tuition classes are arranged for children because parents are busy in jobs 
This statement has explained that parents are busy in their jobs and do not have time to spend on the homework of their children so they have arranged extra tuition classes for their children's. The above figure shows the parents mean as 4.1782 and students mean as 3.4509 . From the analysis it can be concluded that both respondents agreed with the statement but a little difference exist between their responses.

Statement 18: Future profession which the children want to adopt in future is discussed with parents by children

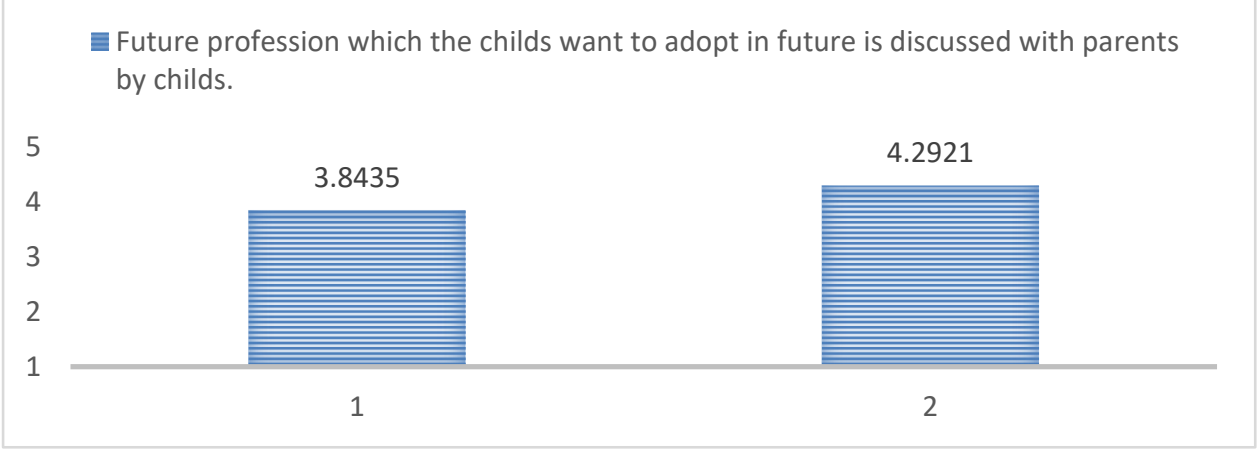

Figure 4.18. Future profession which the children want to adopt in future is discussed with parents by children

This statement has explained that the favorite profession in which children feel interest they discussed with their parents that they want to adopt this profession in their future life. The figure indicates students mean as 4.2921 and the value of parents mean as 3.8435. Through the analysis it can be concluded that students and parents both agreed with the statement just with a little difference in their responses.

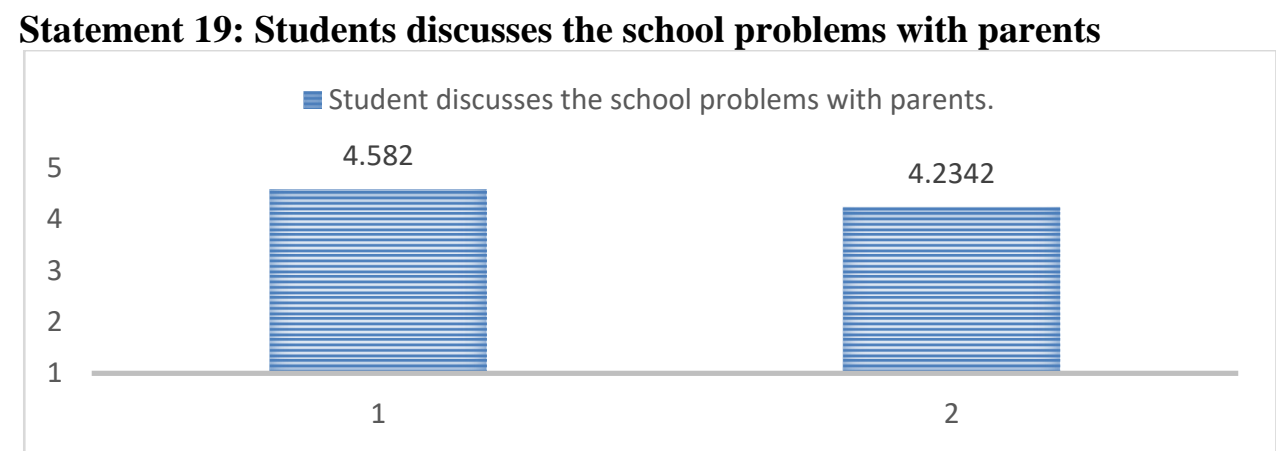

Figure 4.19. Students discusses the school problems with parents

This statement has explained that students feel many problems in their school settings and they discuss all these issues with their parents. The above figure shows the parents mean as 4.582 and students mean as 4.2342 through the analysis it can be concluded that parents and students both agreed with the statement a little difference exist among their responses.

Statement 20: The time which parents and children spend with each other has a positive effect on student's academic success 


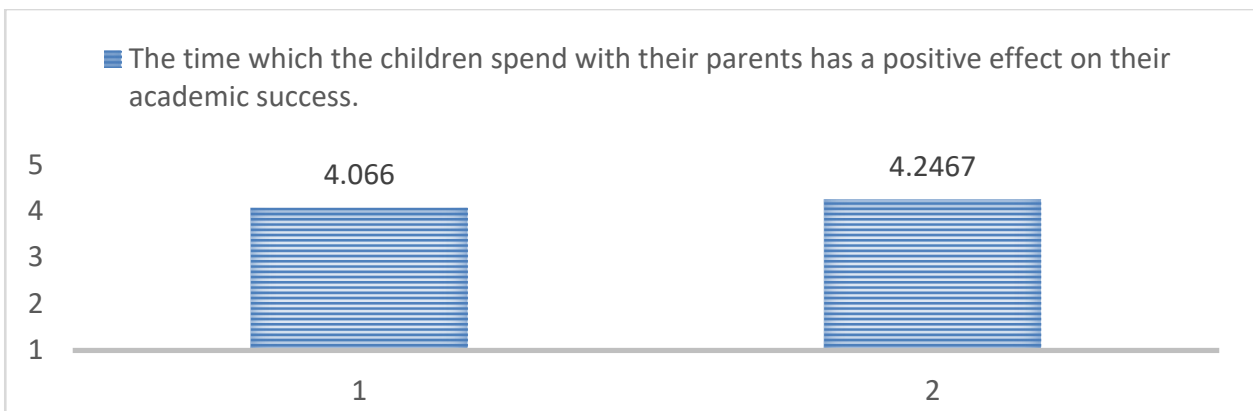

Figure 20. The time which parents and children spend with each other has a positive effect on student's academic success

This statement has explained that the time is very beneficent which the children spend with their parents has an encouraging force for good educational performance of students. The figure shows the mean of students' responses as 4.2467 and parents mean as 4.066. Through the analysis it can be concluded that parents and students agreed with the statement just with a minor difference in their responses.

\section{Finding, Conclusion and Recommendations:}

\subsection{Finding:}

The objective of present study was to explore the involvement of parents in the academic activities of secondary school students in city Kotli AJK. The researchers used survey method for data collection and data was analyzed through SPSS software the mean values of both parents and students' responses were analyzed and represented in graphical form. Through research findings the researcher concluded that the involvement of parents in student's activities creates significant influence on the academic performance of secondary school students in city Kotli AJK. The results of this study have highlighted that parental involvement creates significant influence on the academic success of children. The study has also reflected that parents shows involvement in doing all home-based assignments and other educational activities of their children creates significant influence on their educational performance. Moreover, the study reveals that educated and uneducated both parents consider the education of their children important for them and do not rely on the learning of school teachers but also make efforts for the educational achievement of their children. Furthermore, the findings show that literate and illiterate both parents arrange tuition classes for their children according to their resources and abilities because illiterate parents do not provide proper guidance to their children and literate parents do not have enough time to spend on the academic activities of their children.

\subsection{Recommendations}

In the light of the above findings the researchers recommend the following;

1. This study recommends that parents have to show more involvement and serious attitude toward their children education for the purpose of their secure future.

2. The administration of school may establish and design sustainable guidance and counseling union to effectively deal with the problems of students and also parents. This union shall provide surety to facilitate the students to solve those problems originating from the parental side as well as providing suggestions how to overcome those problems.

3. From the findings it was shown that the time which parents and children spend together creates effect on the academic performance of their children's so this study recommends the parents to give enough time to their children's because it will help children to improve learning progress in school. 
4. This research study recommends that the parents may try to present themselves as a most important leading personality in sustaining the education of their children' because parents are the first teachers of children to represent them the picture or rough sketch of to the educational world. The researcher also recommends parents to create a good relationship with the teachers of their children's for getting more understanding of their children's learning activities for improving their academic performance.

5. The local government at district level may always try to guide and motivate parents to work together with the administration of school through deeply investigating the academic performance of their children's close supervision of their children academic by balancing of home responsibilities with education of child at home. This will help to increase the level of academic achievement of students.

6. This study recommends further research on same topic in elementary or higher secondary level.

\section{References}

Abdu-Raheem, B. O. (2015). Parents' Socio-Economic Status as Predictor of Secondary School Students' Academic Performance in Ekiti State, Nigeria. Journal of Education and practice, 6(1), 123-128.

Aikens, N. L., Coleman, C. P., \& Barbarin, O. A. (2008). Ethnic Differences in The Effects of Parental Depression on Preschool Children's Socioemotional Functioning. Social Development, 17(1), 137-160.

Alba, R., Sloan, J., \& Sperling, J. (2011). The Integration Imperative: The Children Of LowStatus Immigrants in the Schools of Wealthy Societies. Annual Review of Sociology, 37, 395-415.

Alomar, B. O. (2006). Personal and Family Paths to Pupil Achievement. Social Behavior and Personality: An International Journal, 34(8), 907-922.

Barnard, M., \& McKeganey, N. (2004). The Impact of Parental Problem Drug Use on Children: what is the problem and what can be done to help? Addiction, 99(5), 552-559.

Bicer, A., Capraro, M. M., \& Capraro, R. (2013). The Effects of Parent's SES and Education Level on Students' Mathematics Achievement: Examining the Mediation Effects of Parental Expectations and Parental Communication. The Online Journal of New Horizons in Education, 3(4), 89-97.

Bicer, A., Capraro, R. M., \& Cetin, S. C. (2012). Parental Involvement Effects on Students' Mathematics Achievement. Inannual conference of Southwest Educational Research Association (SERA), New Orleans, LA.

Englund, M. M., Luckner, A. E., Whaley, G. J., \& Egeland, B. (2004). Children's Achievement in Early Elementary School: Longitudinal Effects of Parental Involvement, Expectations, and Quality of Assistance. Journal of Educational Psychology, 96(4), 723.

Fann, A., McClafferty Jarsky, K., \& McDonough, P. M. (2009). Parent involvement in the college planning process: A case study of P-20 collaboration. Journal of Hispanic Higher Education, 8(4), 374-393.

Farooq, M. S., Chaudhry, A. H., Shafiq, M., \& Berhanu, G. (2011). Factors Affecting Students Quality of Academic Performance: A Case of Secondary School Level. Journal of quality and technology management, 7(2), 1-14.

Friedel, J. M., Cortina, K. S., Turner, J. C., \& Midgley, C. (2010). Changes in Efficacy Beliefs in Mathematics Across The Transition to Middle School: Examining The Effects 
of Perceived Teacher and Parent Goal Emphases. Journal of educational Psychology, 102(1), 102.

Ginsburg, H. P., Duch, H., Ertle, B., \& Noble, K. G. (2012). How Can Parents Help Their Children Learn Math. Handbook of family literacy, 51-65.

Griffin, K. W., Botvin, G. J., Scheier, L. M., Diaz, T., \& Miller, N. L. (2000). Parenting Practices as Predictors of Substance Use, Delinquency, and Aggression Among Urban Minority Youth: Moderating Effects of Family Structure and Gender. Psychology of addictive behaviors, 14(2), 174.

Kim, E. (2002). The Relationship between Parental Involvement and Children's Educational Achievement in the Korean Immigrant Family. Journal of Comparative Family Studies, 529-540.

Loomans, M. G. (2014). Parent involvement that supports children academically and Promotes the development of independence (Doctoral dissertation, University of Wisconsin-River Falls).

Mutodi, P., \& Ngirande, H. (2014). The impact of parental involvement on student Performance: a case study of a South African secondary school. Mediterranean Journal of Social Sciences, 5(8), 279.

Pashos, C. L., Normand, S. L. T., Garfinkle, J. B., Newhouse, J. P., Epstein, A. M., \& McNeil, B. J. (1994). Trends in the Use Of Drag Therapies in Patients With Acute Myocardial Infarction: 1988 to 1992. Journal of the American College of Cardiology, 23(5), 1023-1030.

Schneider, B., \& Lee, Y. (1990). A Model for Academic Success: The School and Home Environment of East Asian Students. Anthropology \& Education Quarterly, 21(4), 358377.

Schwarz, N., Groves, R. M., \& Schuman, H. (1999). Survey methods. Survey Methodology Program, Institute for Social Research, University of Michigan.

Sui-Chu, E. H., \& Willms, J. D. (1996). Effects of Parental Involvement on Eighth-Grade Achievement. Sociology of education, 126-141.

Ullrich-French, S., \& Smith, A. L. (2006). Perceptions of Relationships with Parents and Peers in Youth Sport: Independent and Combined Prediction of Motivational Outcomes. Psychology of sport and exercise, 7(2), 193-214.

Wang, K. C., Hsieh, A. T., Yeh, Y. C., \& Tsai, C. W. (2004). Who is the Decision-Maker; The Parents or the Child in Group Package Tours. Tourism management, 25(2), 183-194.

Wilder, S. (2014). Effects of Parental Involvement on Academic Achievement: A MetaSynthesis. Educational Review, 66(3), 377-397.

Wright, B. L. (2011). I Know Who I Am, Do You? Identity and Academic Achievement of Successful African American Male Adolescents in an Urban Pilot High School in the United States. Urban Education, 46(4), 611-638. 